\title{
Correlação entre variáveis de densificação do compactador giratório e resistência à deformação permanente de misturas asfálticas convencionais e com resíduos
}

\author{
Felipe Coutinho Onofre ${ }^{1}$; Iuri Sidney Bessa ${ }^{2}$; \\ Verônica Teixeira Franco Castelo Branco ${ }^{3}$ e Jorge Barbosa Soares ${ }^{4}$
}

\begin{abstract}
Resumo: Quando se comparam as metodologias de dosagem Superpave e Marshall de misturas asfálticas, uma das vantagens da primeira é a obtenção do gráfico de compactação. Tem sido verificado para misturas densas e contínuas do tipo Concreto Asfáltico (CA) que determinadas áreas, observadas nesse gráfico, podem diferenciar estas misturas quanto à trabalhabilidade e à resistência à deformação permanente. No presente estudo, os parâmetros Compaction Densification Index (CDI) e Traffic Densification Index (TDI) foram utilizados como indicadores da compactabilidade. Desenvolveu-se um estudo de correlação entre estas variáveis e a resistência à deformação permanente de misturas asfálticas. Foram avaliadas três misturas asfálticas contendo: (i) apenas agregados graníticos, (ii) $50 \%$ de agregados graníticos e $50 \%$ de escória de aciaria e (iii) $50 \%$ de agregados graníticos e $50 \%$ de Resíduo de Construção e Demolição (RCD). As variáveis escolhidas para a determinação da resistência à deformação permanente foram os resultados do ensaio uniaxial de carga repetida (amostras compactadas para dois percentuais de Volume de vazios) e do ensaio com simulador de tráfego laboratorial do tipo LCPC. Foi utilizado também o Processamento Digital de Imagens (PDI) para a determinação da esfericidade dos agregados estudados, propriedade que influencia a resistência à deformação permanente. Os resultados encontrados indicam que as variáveis CDI e TDI podem ser usadas como parâmetros de estudo para prever a resistência à deformação permanente, mesmo para misturas com utilização de resíduos. A caracterização dos agregados através do PDI mostrou que o agregado de origem granítica possui o formato de suas bordas menos próximo ao de uma esfera em relação aos resíduos. Misturas contendo este agregado possuem uma estrutura mais rígida, devido ao maior intertravamento e ao atrito interno entre os agregados, resistindo, assim, melhor à deformação permanente.
\end{abstract}

Palavras-chave: misturas asfálticas; deformação permanente; compactador giratório Superpave; variáveis de densificação.

\begin{abstract}
When comparing the Superpave and the Marshall asphalt mixture design methodologies, an important advantage of the Superpave methodology is the compaction curve. It has been established for dense mixes, such as Hot Mixture Asphalt (HMA), that certain areas in this graph can differentiate mixtures in terms of workability and resistance to permanent deformation. In the present study, the Compaction Densification Index (CDI) and the Traffic Densification Index (TDI) were obtained and correlated to the mixture resistance to permanent deformation. Three mixtures were analyzed: (i) one with $100 \%$ of granitic aggregates, (ii) one with $50 \%$ of granitic aggregates and $50 \%$ of steel slag, and (iii) one with $50 \%$ of granitic aggregates and $50 \%$ of Construction Solid Waste (CSW). Digital Image Processing (DIP) was used to determine the angularity and roundness of the aggregates. Those properties affect the resistance to permanent deformation. Results from dynamic creep (samples compacted with two different air voids contents) and traffic simulation tests were correlated to CDI and TDI values. The results indicated that these variables can be used to predict permanent deformation, even when wastes are used as aggregates in HMA's. The characterization with DIP techniques showed that the granite aggregate has a less spherical shape in comparison to the byproducts. The mixture with granite aggregate has a more rigid structure, because there is a greater interlock and internal friction between the aggregates, leading to better performance with respect to permanent deformation.

Keywords: asphalt mixtures; permanent deformation; Superpave gyratory compactor; densification curves.
\end{abstract}

\section{INTRODUÇÃO}

Nos últimos anos tem sido comum a ocorrência de problemas associados à deformação permanente nos revestimentos asfálticos aplicados em rodovias brasileiras. O que agrava a situação é que este tipo de defeito costuma se manifestar de maneira precoce, comprometendo a serventia dos pavimentos em poucas semanas (Nascimento et al., 2008). A deformação permanente nos revestimentos asfálticos po-

\footnotetext{
${ }^{1}$ Felipe Coutinho Onofre, Laboratório de Mecânica dos Pavimentos, Departamento de Engenharia de Transportes, Universidade Federal do Ceará, Fortaleza, CE, Brasil. (e-mail: fonofre@gmail.com).

${ }^{2}$ Iuri Sidney Bessa, Laboratório de Mecânica dos Pavimentos, Departamento de Engenharia de Transportes, Universidade Federal do Ceará, Fortaleza, CE, Brasil. (e-mail: iuribessa@gmail.com).

${ }^{3}$ Verônica Teixeira Franco Castelo Branco, Laboratório de Mecânica dos Pavimentos, Departamento de Engenharia de Transportes, Universidade Federal do Ceará, Fortaleza, CE, Brasil. (e-mail: veronica@det.ufc.br).

${ }^{4}$ Jorge Barbosa Soares, Laboratório de Mecânica dos Pavimentos, Departamento de Engenharia de Transportes, Universidade Federal do Ceará, Fortaleza, CE, Brasil. (e-mail: jsoares@det.ufc.br).
}

Manuscrito recebido em 27/5/2010 e aprovado para publicação em 6/4/2011. Este artigo é parte de TRANSPORTES v.19, n.1, 2011. ISSN: 2237-1346 (online). de ser definida como depressões longitudinais nas trilhas de roda, as quais aumentam com as cargas repetidas impostas pelo tráfego de veículos (Mahmoud e Bahia, 2004). Para se combater este tipo de defeito em misturas asfálticas se recorre, sobretudo, a agregados com propriedades específicas, embora também a ligantes modificados. A maior preocupação com os agregados é uma das características da metodologia de dosagem Superpave, concebida como produto do Strategic Highway Research Program (SHRP), realizado entre 1987 e 1992, com o objetivo de melhorar a qualidade e a durabilidade dos revestimentos produzidos nos Estados Unidos. Atualmente, essa metodologia tem sido adotada e continuamente refinada por diversos países, e vem sendo pesquisada também no Brasil (Tonial e Leite, 1995; Motta et al., 1996; Viana et al., 1996; Marques, 2004).

Uma das vantagens da utilização da metodologia de dosagem Superpave é a obtenção de um gráfico de compactação que correlaciona a densidade aparente da mistura (expressa em percentual da densidade máxima teórica - $\left.G_{m m}\right)$ a cada giro de compactação com o respectivo número de giro. O estágio imediato de compactação pode fornecer diretamente o Volume de vazios (Vv) na mistura. Além disso, 
Bahia et al. (1998) propuseram que, dessa curva, poderiam ser obtidos parâmetros relativos à estabilidade das misturas dosadas e compactadas segundo a metodologia Superpave. Esses parâmetros são denominados Construction Densification Index (CDI) e Traffic Densification Index (TDI). Desde esse primeiro trabalho, vários outros foram desenvolvidos propondo a utilização da curva de compactação para obtenção de parâmetros que representem a estabilidade de misturas asfálticas. Dessouky et al. (2004) desenvolveram um método que consiste em uma derivação matemática aliada a um procedimento experimental que determina um novo parâmetro de estabilidade denominado Contact Energy Index (CEI). Ele reflete a habilidade da estrutura do agregado de desenvolver contato entre as partículas quando sujeitas à tensão de cisalhamento.

Aragão et al. (2007) avaliaram, por meio dos parâmetros CDI e TDI, a necessidade da zona de restrição como critério limitador de misturas projetadas para suportar baixos volumes de tráfego. Nascimento (2008) verificou, utilizando 22 misturas asfálticas, correlações entre os resultados dos ensaios de simulação de tráfego em laboratório e do uniaxial de carga repetida com os valores das variáveis CDI e TDI. Esse autor mostrou que, para as misturas investigadas, essas variáveis independiam do tipo de ligante utilizado, sendo sensíveis apenas ao intertravamento do esqueleto pétreo. A correlação entre o CDI e o resultado do ensaio de simulação de tráfego apresentou $\mathrm{R}^{2}$ igual 0,78 . As correlações obtidas entre o TDI e os resultados dos ensaios de simulação de tráfego e do uniaxial de carga repetida apresentaram $\mathrm{R}^{2}$ igual a 0,96 e 0,89 , respectivamente.

Vale ressaltar que outros métodos de obtenção das variáveis têm sido estudados, bem como o desenvolvimento de equipamentos com essa finalidade como o Gyratory Load Plate Assembly (GLPA), cuja utilização será explicada na próxima seção. A utilização do Compactador Giratório Superpave (CGS) se mostra bastante razoável pela sua simplicidade e funcionalidade em relação à investigação sobre trabalhabilidade e resistência à deformação permanente em misturas asfálticas.

O objetivo do presente trabalho é verificar a possibilidade da utilização das variáveis CDI e TDI, obtidas a partir da curva de compactação extraída do CGS, para diferenciar misturas asfálticas com utilização de agregados naturais e de resíduos quanto à resistência à deformação permanente. Essa verificação será realizada através da análise de correlações entre as variáveis CDI e TDI e os resultados de Flow Number (FN) obtidos através do ensaio uniaxial de carga repetida (realizado com amostras com dois percentuais de Vv), e os resultados de simulação de tráfego com a utilização de um simulador laboratorial de tráfego do tipo LCPC. Utilizou-se também o Processamento Digital de Imagens (PDI) para a determinação da esfericidade dos agregados, propriedade esta que influencia a resistência à deformação permanente. Três misturas asfálticas com a mesma granulometria, porém com diferentes composições de materiais foram analisadas: (i) contendo apenas agregados graníticos, (ii) contendo $50 \%$ de agregados graníticos e $50 \%$ de escória de aciaria, e (iii) contendo $50 \%$ de agregados graníticos e $50 \%$ de Resíduo de Construção e Demolição (RCD).

\section{FUNDAMENTAÇÃO TEÓRICA}

\subsection{Deformação Permanente}

A deformação permanente é um dos defeitos mais comuns na pavimentação asfáltica, podendo ser atribuída ao revestimento, às subcamadas ou ainda à combinação de defeitos em diversas camadas. A deformação em misturas asfálticas ocorre devido à uma combinação do fluxo de material (viscoelástico ou viscoplástico) e do dano nesse material, representado pela formação e propagação de trincas. A capacidade da mistura asfáltica de resistir a esse tipo de deformação depende de diversos fatores, entre os quais: (i) clima, (ii) consistência do ligante, (iii) volumetria da mistura, e (iv) propriedades de forma, angularidade e textura dos agregados (Bernucci et al., 2007). Para o estudo da deformação permanente em misturas asfálticas, os ensaios mais utilizados são: (i) creep estático, (ii) uniaxial de carga repetida (também chamado de creep dinâmico), (iii) triaxial com carregamento repetido e (iv) simulação em laboratório (Shell, 2003).

\subsection{CDI e TDI}

As variáveis CDI e TDI são obtidas a partir dos dados extraídos da curva de compactação do CGS. CDI é definido como o valor da área entre três curvas: (i) a de compactação, (ii) a reta horizontal que cruza a curva de compactação quando do oitavo giro e (iii) a reta vertical que cruza com a curva de compactação quando a densidade é equivalente a $92 \%$ da $G_{m m}$. TDI é o valor da área entre as seguintes curvas: (i) a de compactação, (ii) a reta horizontal em que se observa $92 \%$ da $G_{m m}$ e (iii) a reta vertical que cruza a curva de compactação quando a densidade aparente é equivalente a $98 \%$ da $G_{m m}$. Há casos em que algumas misturas possuem baixos percentuais de ligante, ou até um alto percentual de agregados graúdos, que impossibilita a determinação do TDI visto que é necessário atingir $98 \%$ da $G_{m m}$ da mistura. Nesse caso, pode ser utilizado o TDI modificado $\left(\mathrm{TDI}_{m}\right)$, que é o valor da área entre as seguintes curvas: (i) a de compactação, (ii) a reta horizontal em que se observa $92 \%$ da $G_{m m}$ e (iii) a reta vertical que cruza a curva de compactação quando a densidade aparente é equivalente a $96 \%$ da $G_{m m}$. Nascimento (2008) relatou que o $\mathrm{TDI}_{m}$, assim como o TDI, apresenta boas correlações com outros resultados de ensaios de deformação permanente, podendo ser utilizado como parâmetro para a determinação da resistência à deformação permanente. A Figura 1 mostra o $\mathrm{TDI}_{m}$, além do CDI e do TDI.

Percebe-se que o CDI se relaciona com a energia despendida em campo durante a construção do revestimento e o TDI com o trabalho realizado pela ação do tráfego durante a vida de serviço do mesmo. Misturas com baixos valores de CDI possuem melhor trabalhabilidade e misturas com altos valores de TDI são mais resistentes à deformação permanente. Trata-se da utilização de parâmetros volumétricos para a descrição de um comportamento mecânico, no caso a resistência à deformação permanente. Surgiram dúvidas no desenvolvimento destes parâmetros, que levaram à criação de um dispositivo que pode ser inserido no topo da mistura a ser compactada. Este dispositivo permite obter informações com relação à distribuição de tensões na amostra, ou seja, parâmetros relativos à resistência à compactação. O equipamento, criado em 2000, foi denominado GLPA (Bahia e Faheem, 2007). Usando-se esse equipamento, foram obtidos resultados referentes à compactabilidade, o Compaction Force Index (CFI) e o Traffic Force Index (TFI), que foram relacionados estatisticamente com os valores de CDI e TDI, apresentando $\mathrm{R}^{2}$ da ordem de 0,95. Sendo assim, as duas variáveis volumétricas passaram a pa- 


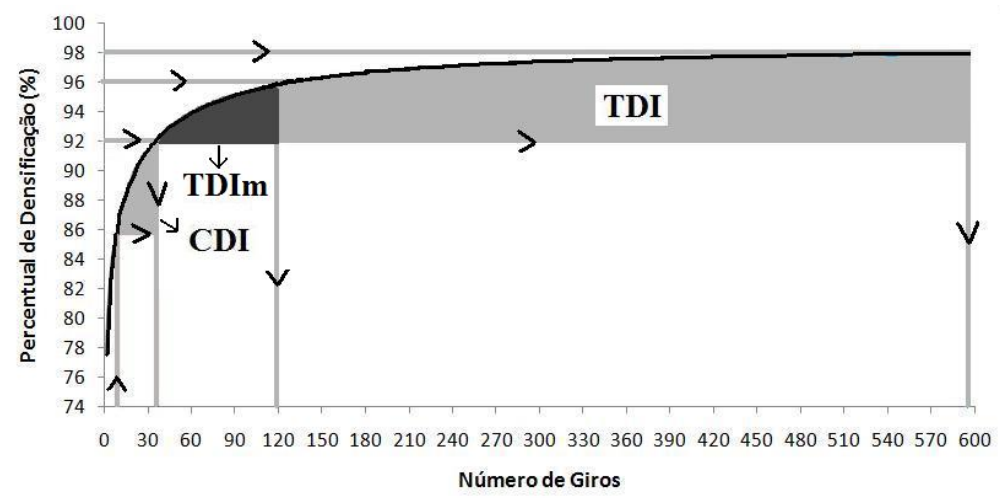

Figura 1. Determinação do CDI, TDI e TDI $m$ a partir da curva de compactação do CGS

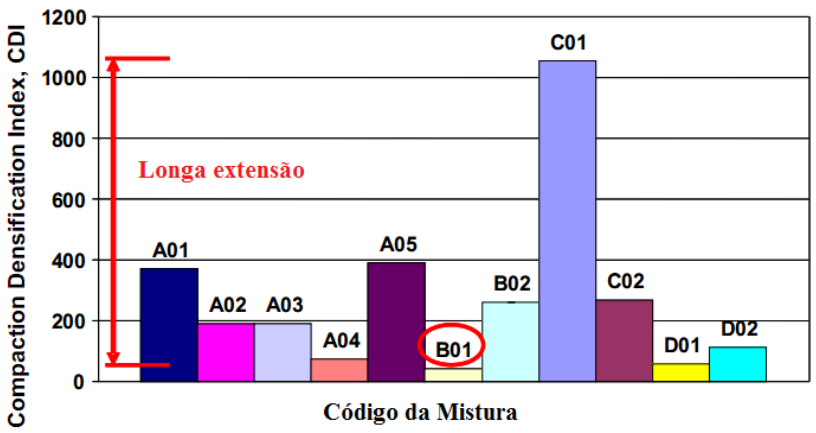

(a)

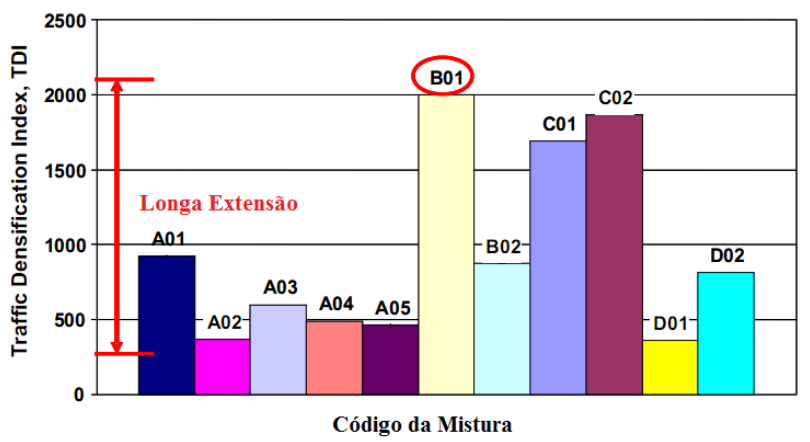

(b)

Figura 2. Média de valores de (a) CDI e (b) TDI encontrados nas misturas estudadas por Mahmoud e Bahia (2004)

recer válidas conceitualmente.

Mahmoud e Bahia (2004) realizaram um estudo estatístico para correlacionar as variáveis CDI e TDI com resultados de FN obtidos pelo ensaio uniaxial de carga repetida. No referido trabalho, obtiveram $\mathrm{R}^{2}$ da ordem de 0,80 , indicando o potencial do TDI para diferenciar misturas quanto à resistência à deformação permanente. Concluiu-se que, quanto maior o FN, maior deve ser o valor do TDI. Alguns valores de CDI e TDI estão mostrados na Figura 2.

Percebe-se que as misturas do tipo B01, circuladas na Figura 2, apresentaram os menores valores de CDI e os maiores valores de TDI. Misturas com baixos valores de CDI possuem alta facilidade de execução em campo devido à necessidade de uma baixa energia de compactação e misturas com altos valores de TDI possuem uma forte resistência à densificação causada pelo tráfego, o que dificulta o processo de deformação permanente do revestimento asfáltico. Um alto valor de TDI pode estar associado ao intertravamento, à textura, à forma, ou à angularidade dos agregados. As misturas do tipo B01 eram formadas por agregados com dimensões de $3 / 4$ ", $3 / 8$ ", $1 / 2$ " e $1 / 8$ " com os percentuais de $20,30,25$ e 25 , respectivamente, tendo, esses agregados, diferentes origens mineralógicas. As misturas do tipo B01 foram confeccionadas com $6,2 \%$ de ligante, classificado como PG 64-28. O esqueleto pétreo é sabidamente mais determinante quando se trata de resistência a deformação permanente. Por exemplo, misturas com um bom projeto do esqueleto pétreo e ligante pouco consistente tendem a apresentar desempenho mais satisfatório do que misturas com um esqueleto mal projetado, mesmo que com um ligante mais consistente (Nascimento, 2008; Souza, 2009). A angularidade dos agregados graúdo e miúdo garante o atrito entre as partículas que propicia a resistência à deformação permanente. A forma da partícula influi na trabalhabilidade e muda a energia de compactação necessária para se alcançar a densidade desejada. Partículas irregulares ou de forma mais angular tendem a apresentar melhor intertravamento entre os grãos compactados, tanto quanto mais cúbicas forem as partículas e mais pontiagudas forem as suas arestas (Bernucci et al., 2007). 


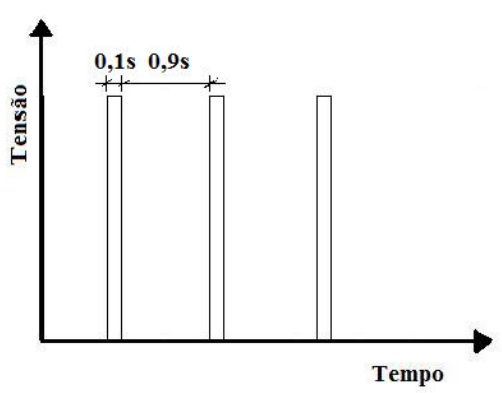

(a)

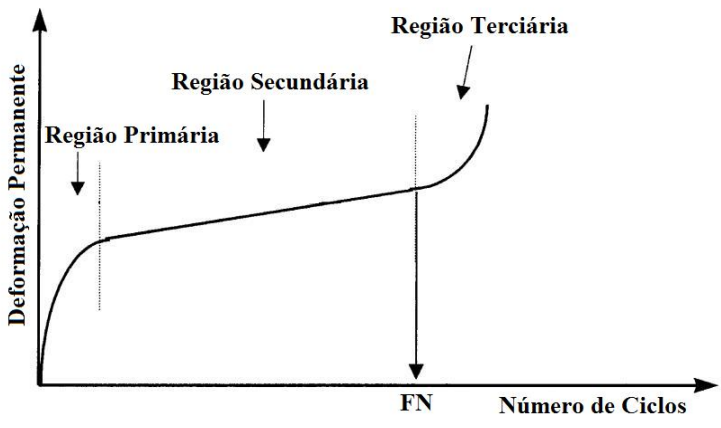

(b)

Figura 3. (a) Aplicação de carga durante o ensaio uniaxial de carga repetida e (b) desenvolvimento da deformação permanente durante o ensaio uniaxial de carga repetida e obtenção do FN

\subsection{Ensaio uniaxial de carga repetida (creep dinâmico)}

O ensaio uniaxial de carga repetida é um ensaio simples de ser realizado e que apresenta potencial de correlação com o desempenho de misturas asfálticas em campo. A mistura asfáltica é submetida a um carregamento cíclico de compressão com frequência de $0,1 \mathrm{~s}$ de carga e $0,9 \mathrm{~s}$ de descanso, com uma carga de $5 \%$ da carga aplicada no período de $0,1 \mathrm{~s}$, que representa o repouso. As deformações acumuladas são obtidas em função do número de ciclos. O ensaio é realizado à temperatura de $60^{\circ} \mathrm{C}$. A tensão aplicada em cada ciclo é de $204 \mathrm{kPa}$ no período de $0,1 \mathrm{~s}$ e de $5,2 \mathrm{kPa}$ durante os $0,9 \mathrm{~s}$ de repouso. Os corpos de prova (CPs) utilizados no ensaio devem ter $15 \mathrm{~cm} \pm 0,25 \mathrm{~cm}$ de altura e $10 \mathrm{~cm}$ de diâmetro. O FN é o número do ciclo em que o estágio terciário se inicia, que é o ponto em que a taxa de deformação plástica é mínima e a partir do qual o $\mathrm{CP}$ atinge a ruptura. O procedimento descrito anteriormente é detalhado no Report 465 National Cooperative Highway Research Program (NCHRP) (Witczak et al., 2002). A Figura 3 mostra a aplicação da carga durante o ensaio e o ponto em que o FN é atingido.

\subsection{Ensaio de simulação de tráfego em laboratório com uso de simulador do tipo LCPC}

Um dos maiores desafios da engenharia rodoviária é estimar, de forma satisfatória, a vida útil de pavimentos novos e restaurados. Em geral, são realizados testes em laboratórios, em escala reduzida (Fritzen, 2005). Na investigação da deformação permanente em misturas asfálticas, há diferentes simuladores de tráfego em escala laboratorial, com seus respectivos métodos de compactação (Bernucci et al., 2007). Um destes simuladores, com largo histórico de uso na França e também no Brasil, é o do tipo LCPC. Trata-se de um teste que submete misturas asfálticas a condições próximas às encontradas em campo no que diz respeito à temperatura do revestimento e à natureza dos carregamentos.

$\mathrm{O}$ ensaio é realizado a $60^{\circ} \mathrm{C}$ em um par de placas asfálticas com dimensões de $2,5 \times 13 \times 35 \mathrm{~cm}$. As placas são submetidas a 30.000 ciclos de passagem, sendo um ciclo igual a uma passagem em cada sentido do eixo longitudinal da placa asfáltica. Primeiramente, as placas são submetidas a 1.000 ciclos de passagem à temperatura ambiente para serem acomodadas no simulador. A pressão nos pneus e no eixo deve ser de 6 bar. Ao final dos 1.000 ciclos iniciais é realizada uma medição da altura das placas em 15 pontos diferentes. Esses pontos são especificados pela norma fran- cesa NF P 98-253-1 (1991). Em seguida, o simulador deve ser programado para atingir a temperatura de $60^{\circ} \mathrm{C}$. As placas devem ser confinadas a essa temperatura por 12 horas antes que os outros 30.000 ciclos sejam iniciados. São realizadas paradas durante o ensaio para medir os afundamentos de trilha de roda (ATR) nos ciclos $n^{\circ} 100,300,1.000$, $3.000,10.000$ e 30.000 . A norma ainda especifica os procedimentos de processamento de dados. Para uma mistura ser considerada resistente à deformação permanente, esta deve apresentar limite máximo de $10 \%$ de ATR aos 30.000 ciclos à $60^{\circ} \mathrm{C}$.

\subsection{Caracterização de agregados através do Processamento Digital de Imagens (PDI)}

A resistência à deformação permanente está intimamente ligada às características do agregado como angularidade e forma, que interferem no intertravamento do esqueleto pétreo. Essas características podem ser determinadas por meio de ensaios de caracterização manuais ou por meio de PDI (Evangelista et al., 2005). A técnica do PDI, utilizada no presente trabalho, envolve a digitalização da imagem real de partículas de agregado e sua análise a fim de caracterizar os mesmos, obtendo parâmetros relacionados à forma. Esta técnica consiste de algumas etapas até que os dados requeridos sejam extraídos. O software Imagetool é uma ferramenta que pode ser utilizada para a análise de imagens e processamento de dados, sendo possível alterar a resolução de imagens e converter seu formato (Bessa et al., 2009).

Para a análise dos parâmetros relacionados à forma das partículas de agregados, primeiro deve ser realizada a etapa de digitalização, ou seja, o processo de transformação da imagem real de um objeto físico em uma imagem digital que possa ser manipulada em um computador. Para que cada partícula do conjunto de agregados tenha sua forma bem definida, é necessária a etapa de realce. Nessa etapa, são detectadas as bordas de cada uma das partículas. A etapa de restauração procura corrigir os defeitos e as imperfeições que possivelmente possam ter aparecido devido ao processo de digitalização da imagem. Por fim, faz-se necessária a identificação e a rotulação de cada partícula de agregado para que possam ser tratadas e analisadas separadamente (Souza et al., 2006). O nível dessa subdivisão depende do objetivo que se quer alcançar (Gonzalez e Woods, 1993). Logo, como é possível a identificação de uma imagem, todas as sub-imagens e objetos pertencentes a ela podem ser também identificados e localizados. Assim, pode ser feita a determinação de propriedades como área, perímetro, orien- 
Tabela 1. Resultados da caracterização dos agregados: convencionais e resíduos

\begin{tabular}{|c|c|c|c|c|c|c|}
\hline \multirow[b]{2}{*}{ Característica } & \multicolumn{3}{|c|}{ Agregado Granítico } & \multicolumn{2}{|l|}{$R C D$} & \multirow{2}{*}{$\begin{array}{l}\text { Escória de } \\
\text { Aciaria }\end{array}$} \\
\hline & Brita 3/4" & Brita 3/8" & Pó de pedra & Graúdo & Miúdo & \\
\hline Abrasão Los Angeles (\%) & 42,20 & 42,20 & - & 32,70 & - & 20,40 \\
\hline Absorção - graúdo (\%) & 0,62 & 1,20 & - & 3,50 & - & 1,04 \\
\hline Densidade real & 2,66 & 2,66 & 2,67 & 2,21 & 2,58 & 3,63 \\
\hline Densidade aparente & 2,62 & 2,58 & - & 2,34 & - & 3,35 \\
\hline Adesividade & Satisfatória & Satisfatória & - & Satisfatória & - & Satisfatória \\
\hline Índice de forma & 0,66 & 0,66 & - & 0,85 & - & 0,80 \\
\hline
\end{tabular}

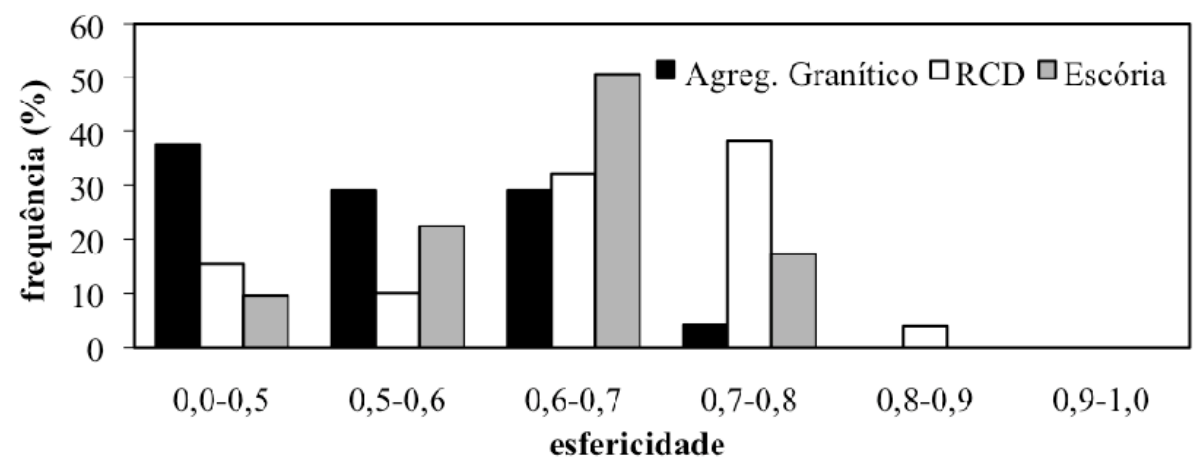

Figura 4. Esfericidade para os três agregados (PDI) (Bessa et al., 2009)

tação, forma, dentre outras. Tecnicamente, a detecção de bordas é o processo de localização dos pixels que separam os objetos a serem identificados dentro da imagem do background, ou seja, todo o resto (Evangelista et al., 2005).

Com a utilização do PDI, é possível obter mais facilmente características relacionadas à forma dos agregados, incluindo perímetro e área. Assim, parâmetros, como esfericidade, podem ser calculados com maior precisão, apresentando uma caracterização mais realista dos agregados (Masad e Button, 2000). Com o PDI, a esfericidade pode ser medida por meio do parâmetro roundness, que possui valores no intervalo entre 0 e 1 . Quanto mais próximo de 1 for o resultado, mais circular é o objeto. Se o resultado da análise for igual a 1 , o objeto terá o formato de um círculo perfeito. $\mathrm{O}$ valor do roundness (r) é obtido através da equação:

$$
r=\frac{4 \times \pi \times A}{P^{2}}
$$

em que,

$A$ : área da partícula; e

$P$ : perímetro da partícula.

\section{MATERIAIS E MÉTODOS}

\subsection{Agregados}

Os agregados naturais de origem granítica utilizados nessa pesquisa foram provenientes da pedreira de Itaitinga, localizada a aproximadamente $30 \mathrm{~km}$ de Fortaleza-CE. O material foi caracterizado seguindo a metodologia recomendada pelo Departamento Nacional de Infra-Estrutura de Transportes (DNIT). Foram realizados ensaios de granulometria (DNER - ME 83/98), abrasão Los Angeles (DNER-ME 35/98), densidade do agregado miúdo e graúdo (DNER-ME 81/98 e DNER-ME 84/95), adesividade (DNER - ME 78/94) e índice de forma (DNER-ME 86/94). Foram usados ainda nesta pesquisa dois resíduos ambientais: (i) RCD, proveniente da usina de reciclagem de Fortaleza (Usifort), e (ii) escória de aciaria, proveniente da Multserv Ltda. locali- zada em Maracanaú, região metropolitana de Fortaleza. Ambos também foram caracterizados seguindo a metodologia do DNIT descrita anteriormente (Tabela 1). Antunes et al. (2010) realizaram ensaios de solubilização e lixiviação no RCD e na escória de aciaria e os dois foram classificados como resíduos não perigosos e inertes. No entanto, na mistura contendo escória de aciaria foi detectada uma concentração de fenóis acima do permitido, caracterizando a mistura como resíduo perigoso. $\mathrm{O}$ mesmo não ocorreu para aquela com a utilização do RCD.

Foi feita a caracterização dos agregados graúdos através do PDI. O parâmetro relacionado à esfericidade foi analisado por meio da imagem obtida com a fotografia dos agregados estudados soltos e dispostos em um plano. Para uma melhor visualização dos agregados na imagem, o fundo utilizado para os agregados graníticos e para o RCD foi de cor preta, enquanto o fundo do plano utilizado para a escória de aciaria foi de cor branca. Os agregados foram colocados de forma a tentar obter os valores dos comprimentos da maior e da menor face de cada uma das partículas. Assim, fotografias foram transformadas em imagens em escalas de cinza e, por meio do software Adobe Photoshop, foram submetidas às demais etapas que compõe o PDI: realce, restauração, segmentação, e detecção de bordas. Os objetos das imagens foram identificados e analisados pelo software Imagetool (http://ddsdx.uthscsa.edu/dig/itdesc.html). Para o parâmetro esfericidade, que resulta em valores relacionados à forma dos agregados, as frequências para cada faixa de valor dos resultados obtidos encontram-se na Figura 4.

A análise da esfericidade mostra que o agregado granítico é menos esférico do que os resíduos, por possuir uma grande quantidade de partículas com valor de esfericidade menor do que 0,6 . O RCD e a escória de aciaria possuem uma grande quantidade de partículas com esfericidade maior do que 0,6 , indicando que são bastante esféricos. O RCD possui forma mais próxima de uma esfera em relação aos outros agregados, com um grande número de partículas cujo valor de esfericidade é maior do que 0,7. Esses resultados são mais precisos do que aqueles obtidos por meio de 


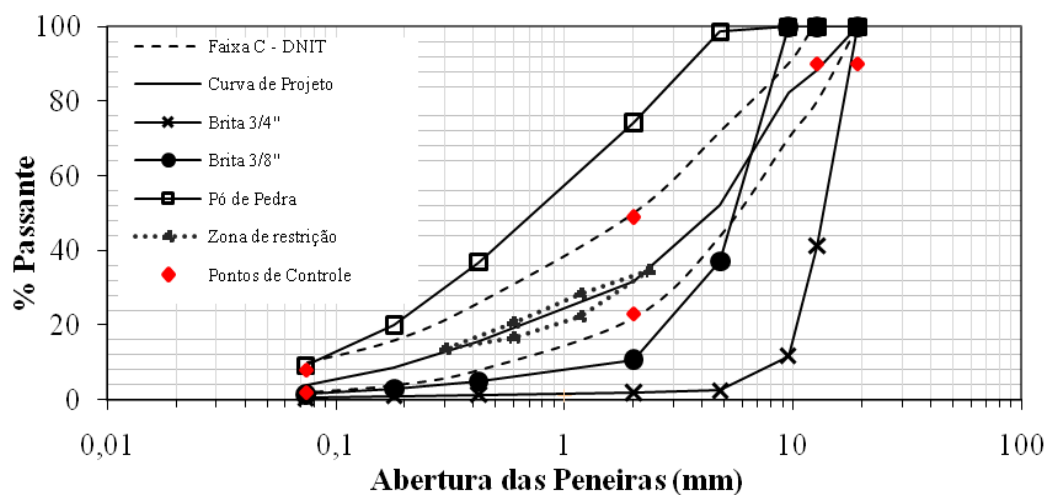

Figura 5. Curva de projeto e granulometria dos agregados naturais utilizados

Tabela 2. Parâmetros da dosagem Superpave

\begin{tabular}{|c|c|c|c|}
\hline \multirow[b]{2}{*}{ Parâmetros } & \multicolumn{3}{|l|}{ Misturas } \\
\hline & CA (sem residuo) & CA (50\% de escória) & $C A(50 \%$ de $R C D)$ \\
\hline Teor de ligante $(\%)$ & 6,0 & 6,6 & 6,9 \\
\hline Vv $(\%)$ & 3,9 & 3,9 & 4,0 \\
\hline$G_{\mathrm{mm}}$ & 2,400 & 2,732 & 2,322 \\
\hline
\end{tabular}

ensaios manuais, além de serem valores estatísticos, permitindo um maior detalhamento da forma de cada partícula.

\subsection{Ligante}

O ligante utilizado é caracterizado por penetração como Cimento Asfáltico de Petróleo (CAP) 50/70 de acordo com especificações brasileiras regulamentadas pela Agência Nacional de Petróleo (ANP, 2005), sendo proveniente do campo Fazenda Alegre no Espírito Santo. O CAP foi fornecido pela Lubrificantes e Derivados de Petróleo do Nordeste (Lubnor), refinaria da Petrobras situada na cidade de Fortaleza.

\subsection{Dosagem das misturas e obtenção das variáveis de densificação CDI e TDI}

As misturas foram dosadas de acordo com a metodologia Superpave, para misturas do tipo CA. O N $\mathrm{N}_{\text {PROJETo adotado }}$ para um volume de tráfego de médio a alto é igual a 100 giros. Definiu-se, primeiramente, uma curva granulométrica característica de um $\mathrm{CA}$ que se enquadrasse na faixa $\mathrm{C}$ do DNIT. A curva de projeto, mostrada na Figura 5, contém $20 \%$ de brita $3 / 4$ ", $36 \%$ de brita $3 / 8$ " e $44 \%$ de pó-de-pedra. A Figura 5 também mostra as faixas de tolerância, a zona de restrição e os pontos de controle para um Tamanho Máximo Nominal (TMN) de 19mm. Para cada teor de ligante estimado, determinaram-se a $G_{m m}$ e o Vv da mistura. Para a confecção dos CPs, o ligante foi aquecido à temperatura de $165^{\circ} \mathrm{C}$ e os agregados a $175^{\circ} \mathrm{C}$. As misturas foram envelhecidas por duas horas em estufa a $160^{\circ} \mathrm{C}$.

A dosagem das misturas com escória de aciaria e RCD foi realizada de forma a manter a mesma granulometria da mistura sem resíduo. O teor de projeto das misturas variou devido à mudança da composição dos materiais. Duas das misturas estudadas continham $50 \%$ de resíduo. A granulometria da mistura sem resíduo foi usada para formar as misturas com os resíduos, de forma que houvesse a substituição dos grãos de agregados retidos em cada peneira por grãos de escória de aciaria e de RCD de tamanho equivalente, mantendo constante a granulometria em cada nova mistura. Como a escória de aciaria apresenta uma densidade maior do que a dos agregados convencionais e a do RCD, sua substituição foi diferenciada devido à correção da curva granulométrica. Essa correção foi baseada no procedimento adotado por Silva (2006). A Tabela 2 mostra os parâmetros de dosagem das misturas sem resíduo, bem como aqueles encontrados para as misturas com os resíduos.

Após determinados os teores de projeto de todas as misturas, foram compactados CPs com esses teores. Para a obtenção dos valores de CDI e TDI foram compactados cinco CPs com 1.000 giros para cada mistura para garantir que os $98 \%$ de densificação fossem atingidos. Foram, ainda, compactados CPs no teor de projeto para o ensaio uniaxial de carga repetida com $\mathrm{Vv}$ iguais a $7 \% \pm 0,5 \%$ e $4 \% \pm 0,5 \%$. O percentual de $7 \% \pm 0,5 \%$ é recomendado pelo NCHRP na avaliação da resistência à deformação permanente (Nascimento, 2008). Foram moldadas seis placas asfálticas de cada mistura para a realização do ensaio de simulação. Duas placas foram utilizadas no ensaio e uma terceira placa foi utilizada para verificar o $\mathrm{Vv}$ da mistura após a compactação por meio de uma vigota $(2,5 \times 13 \times 35 \mathrm{~cm})$ extraída da mesma (Lopes et al., 2010). A três últimas placas foram utilizadas para a extração de quatro CPs de cada, também para a verificação dos Vvs. A compactação das placas foi realizada de acordo com a norma francesa NF P 98-250-2. Os Vvs encontrados por Lopes et al. (2010) são apresentados na Tabela 3. Percebe-se que os valores de Vv na mistura sem resíduos são maiores do que os demais, tanto nas vigotas como nos CPs extraídos, seguidos pelos valores da mistura com $50 \%$ de escória e depois pela mistura com 50\% de RCD. Um alto valor de Vv pode indicar uma alta resistência à densificação pela compactação.

\section{RESULTADOS E DISCUSSÕES}

\subsection{Obtenção das variáveis CDI e TDI}

Após a compactação com 1.000 giros, são extraídas as alturas dos CPs de cada giro para o cálculo do CDI e do TDI. Primeiramente, estima-se a massa específica aparente $\left(G_{m b}\right)$ para cada giro por meio da divisão da massa seca do CP pe- 
Tabela 3. Vvs dos CPs e das vigotas extraídas das placas (Lopes et al., 2010)

\begin{tabular}{|c|c|c|c|c|c|}
\hline Parâmetros & Placa 1 (4 CP's) & Placa 2 (4 CP's) & Placa 3 (4 CP's) & $\begin{array}{l}\text { Placa } \\
\text { Referência }\end{array}$ & $\begin{array}{l}\text { Placas } \\
\text { Simuladas }\end{array}$ \\
\hline & \multicolumn{5}{|l|}{ CA (Sem Residuo) } \\
\hline Vv média (\%) & 7,5 & 7,6 & 7,2 & 5,8 & 4,6 \\
\hline $\mathrm{Vv} C V(\%)^{*}$ & 4,2 & 4,7 & 6,6 & - & - \\
\hline \multicolumn{6}{|c|}{$C A(50 \%$ agregado granítico e $50 \%$ RCD) } \\
\hline Vv média (\%) & 2,6 & 2,8 & 2,7 & 2,4 & 2,0 \\
\hline $\mathrm{Vv} C \mathrm{~V}(\%)^{*}$ & 16,2 & 8,8 & 9,3 & - & - \\
\hline \multicolumn{6}{|c|}{ CA (50\% agregado granítico e 50\% Escória de aciaria) } \\
\hline Vv média (\%) & 3,3 & 3,7 & 3,8 & 3,4 & 1,3 \\
\hline Vv CV $(\%)^{*}$ & 20,4 & 15,8 & 15,1 & - & - \\
\hline
\end{tabular}

*Mesmo cientes da limitação do número de CPs, os autores optaram por registrar este parâmetro:

Coeficiente de Variação $(\mathrm{CV})=$ [desvio-padrão do Vv (\%) dividido pela média do $\mathrm{Vv}(\%)] \times 100$

Tabela 4. Valores de CDI e TDI

\begin{tabular}{|c|c|c|c|c|c|}
\hline \multirow[b]{2}{*}{ Mistura } & \multirow[b]{2}{*}{ Composição } & \multicolumn{2}{|l|}{$C D I$} & \multicolumn{2}{|l|}{$T D I$} \\
\hline & & Média & $C V(\%) *$ & Média & $C V(\%) *$ \\
\hline I & Sem resíduo & 143 & 12 & 2.006 & 9 \\
\hline II & $50 \%$ de agregado granítico e $50 \%$ de RCD & 179 & 15 & 1.929 & 23 \\
\hline III & $50 \%$ de agregado granítico e $50 \%$ de escória de aciaria & 194 & 25 & 1.738 & 28 \\
\hline
\end{tabular}

Coeficiente de Variação $(C V)=($ desvio-padrão do CDI ou TDI dividido pela média do CDI ou TDI $) \times 100$

lo seu volume. Em seguida, corrige-se a $G_{m b}$ estimada para cada giro a partir da $G_{m b}$ medida do milésimo giro. Isso é feito porque o compactador calcula o volume do cilindro considerando que ele é perfeito. Essa correção é feita pela multiplicação da $G_{m b}$ estimada de cada giro pela razão entre a $G_{m b}$ medida e a $G_{m b}$ estimada do milésimo giro. Divide-se a $G_{m b}$ corrigida pela $G_{m m}$ para obter o percentual de densificação da cada giro. Para obter o CDI, calcula-se o somatório de cada área da curva de compactação compreendida pelo espaço entre: (i) a curva de compactação, (ii) dois giros consecutivos e (iii) o percentual de densificação relativo ao oitavo giro. Esse somatório engloba do oitavo giro ao giro correspondente a $92 \%$ de densificação. O TDI é obtido pelo cálculo do somatório de cada área da curva de compactação compreendida entre: (i) o espaço entre a curva de compactação, (ii) dois giros consecutivos e o (iii) percentual de densificação igual a 92\%. Esse somatório engloba a faixa de giros correspondente a 92 e $98 \%$ de densificação. Foram compactadas cinco amostras para cada mistura estudada. Utilizou-se um programa desenvolvido por meio da linguagem $\mathrm{C}++$ para auxiliar no processamento e compilação dos dados gerados. A Tabela 4 mostra os resultados de CDI e TDI obtidos.

Os resultados indicam diferenças tanto nos resultados de CDI, quanto nos resultados de TDI para as três misturas analisadas. A mistura sem resíduo apresentou CDI mais baixo, o que indica que esta possui maior facilidade para compactação. As misturas contendo os resíduos apresentaram resultados de CDI maiores quando comparadas a mistura com agregado natural, sendo o valor da mistura com RCD um pouco inferior ao valor da mistura com escória de aciaria. As misturas com os resíduos possuem um teor de ligante mais elevado, o que facilitaria o preenchimento de vazios na mistura mais rapidamente e com isso esperava-se que elas obtivessem menores valores de CDI. No entanto, como os resíduos possuem maior absorção, acredita-se que parte do ligante concentrou-se no interior dos agregados. Portanto, os valores superiores de CDI encontrados para essas misturas podem estar associados às propriedades dos agre- gados, principalmente à forma. Os resultados de TDI mostraram-se mais satisfatórios (maiores) para a mistura apenas com agregado natural, o que a torna mais resistente à densificação causada pelo tráfego. Esses resultados, no entanto, não apresentaram grande diferença, sendo de $13 \%$ a maior delas, entre a mistura apenas com agregados naturais e a mistura com escória de aciaria. No caso do CDI essas misturas apresentaram $26 \%$ de diferença. As amostras das misturas sem resíduo apresentaram CV menores do que as misturas com resíduo. Isso era esperado pelo fato dos resíduos serem materiais mais heterogêneos, levando, portanto, a uma maior dispersão nos resultados.

Os valores (CDI e TDI) obtidos por Aragão et al. (2007) foram aproximadamente $50 \%$ menores do que os valores obtidos no presente estudo. As cinco misturas avaliadas por Aragão et al. (2007), CAs com a parte graúda constante e a parte miúda variando abaixo da peneira \#4, apresentaram comportamento semelhante ao grupo de misturas C02 estudado por Mahmoud e Bahia (2004). Esse grupo é composto por misturas que possuem em sua maior parte agregados miúdos e o seu teor de projeto de ligante (PG 58-28) igual a $5 \%$.

\subsection{Obtenção dos resultados de FN e correlação com as variáveis CDI e TDI}

Foram realizados três ensaios uniaxiais de carga repetida por mistura para cada percentual de Vv (4 e 7\%), totalizando 18 ensaios. $\mathrm{O}$ equipamento utilizado para o ensaio foi a máquina universal de ensaios (UTM 25 - Universal Testing Machine). Para cada ensaio, o equipamento foi programado com os parâmetros descritos anteriormente juntamente com os LVDTs, medidores de deformação axial de alta precisão. O objetivo do ensaio é obter o FN, que é dado no ciclo em que a taxa de deformação plástica é mínima. Os valores encontrados nos ensaios estão na Tabela 5.

A mistura contendo apenas agregados naturais com 7\% de $\mathrm{Vv}$ apresentou $\mathrm{FN}$ mais elevado quando comparada às outras misturas, o que é vantajoso, pois quanto maior o FN maior será a resistência à deformação permanente da mistura. A mistura com RCD apresentou resultados inferiores ao 
Tabela 5. Valores de FN

\begin{tabular}{lclc}
\hline Mistura & Teor de Ligante $(\%)$ & $\boldsymbol{F N}(\boldsymbol{V} \boldsymbol{v}=\mathbf{4 \%} \mathbf{0 0 , 5 \%})$ & $\boldsymbol{F N}(\boldsymbol{V v}=\mathbf{7 \%} \pm \mathbf{0 , 5 \%})$ \\
\hline I (Sem resíduo) & 6,0 & 610 & 317 \\
II (50\% de RCD) & 6,9 & 739 & 201 \\
III (50\% de escória de aciaria) & 6,6 & 884 & 171 \\
& 3,8 & - & 620 \\
Nascimento (2008) & 4,0 & - & 110 \\
& 4,1 & - & 464 \\
& 4,3 & - & 6.751 \\
Mahmoud e Bahia (2004) & 4,5 & - & 2.263 \\
\hline
\end{tabular}

da mistura contendo apenas agregados naturais, porém eles foram mais satisfatórios do que os resultados da mistura com escória de aciaria. As misturas ensaiadas com $4 \%$ de $\mathrm{Vv}$ apresentaram um ranking oposto ao encontrado com as misturas ensaiadas com $7 \%$ de Vv. Essa diferença provavelmente ocorreu porque os resultados deste ensaio são mais sensíveis do que aqueles encontrados para amostras moldadas com 7\% de Vv (maior probabilidade de densificação). Os resultados numéricos de Nascimento (2008) foram relativamente próximos aos encontrados nesse estudo. Os resultados de Mahmoud e Bahia (2004) foram bem maiores aos encontrados nessa pesquisa. A Figura 6 mostra a correlação entre TDI e FN para as três misturas estudadas com dois \% de Vv.

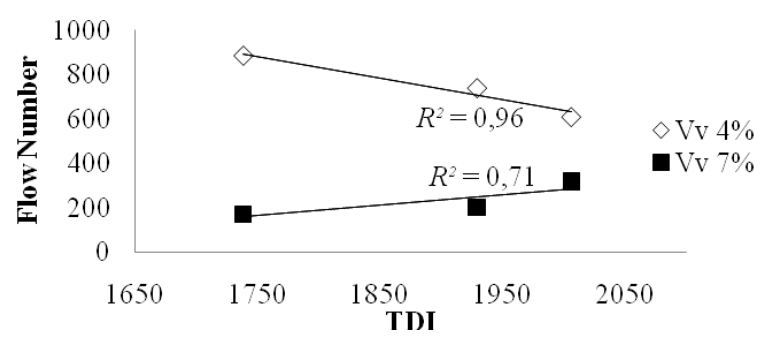

Figura 6. Correlação entre TDI e FN para os dois percentuais de $V_{v}$

As variáveis TDI apresentaram uma boa correlação com os resultados de FN com $7 \%$ de $\mathrm{Vv}$, com $R^{2}=0,71$. Mahmoud e Bahia (2004) obtiveram $R^{2}=0,79$ e Nascimento (2008) obteve $R^{2}=0,89$, similares, portanto, ao encontrado nas misturas com $7 \%$ de $\mathrm{Vv}$ avaliadas no presente estudo. Isso indica que as variáveis de densificação podem ser consideradas para o estudo da resistência à deformação permanente em misturas asfálticas convencionais e também com utilização de resíduos, que é uma contribuição do presente estudo. As variáveis de densificação também apresentaram uma boa correlação com os ensaios de FN com amostras com $4 \%$ de $\mathrm{Vv}$, porém a tendência dessa correlação foi diferente da correlação das misturas com $7 \%$ de Vv. Nas amostras com $4 \%$ de $\mathrm{Vv}$ houve uma diminuição do FN com o aumento do TDI, o que mostra a grande influência no $\mathrm{Vv}$ das misturas na resistência à deformação permanente. Apesar do $R^{2}$ da correlação do TDI com o FN com $4 \%$ de VV ter sido maior do que o $R^{2}$ da correlação do TDI com FN com $7 \%$ de $\mathrm{Vv}$, ela não é considerada satisfatória porque esperava-se o aumento do FN com o aumento do TDI.

\subsection{Obtenção dos resultados do ensaio de simulação e correlação com as variáveis CDI e TDI}

Foi realizado um ensaio de simulação por mistura (duas placas por ensaio). $\mathrm{O}$ equipamento usado para a compacta- ção das placas asfálticas foi a mesa compactadora desenvolvida no LCPC. O simulador de tráfego de laboratório utilizado também foi desenvolvido no LCPC. Ambos os equipamentos pertencem à Escola Politécnica da USP. A compactação e a simulação das placas asfálticas foram realizadas seguindo as normas francesas citadas anteriormente. O objetivo do ensaio é obter as deformações das placas nos ciclos pré-definidos. Essas deformações, após os dados serem processados, são dadas em percentuais de ATR. A Figura 7 mostra os resultados dos ensaios de simulação das três misturas estudadas.

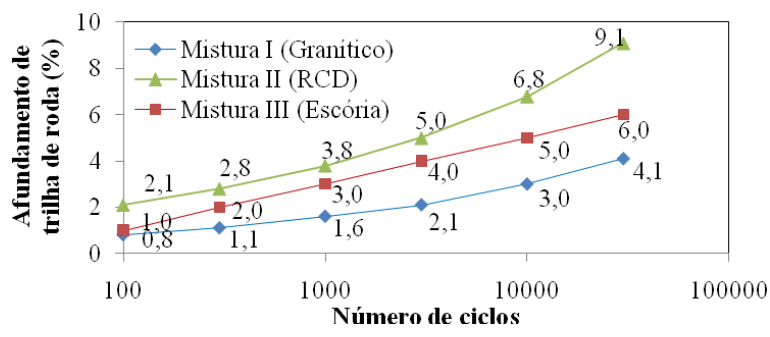

Figura 7. Resultados do ensaio de simulação das três misturas estudadas

A mistura sem resíduo mais uma vez comportou-se melhor do que as misturas com resíduo, sendo que todas apresentaram resultados menores do que $10 \%$ de ATR, o que é aceitável segundo a norma francesa. Ao contrário dos resultados de CDI, TDI e FN, nesse ensaio de simulação a mistura com escória de aciaria apresentou valores mais satisfatórios se comparada à mistura com RCD. O PDI mostrou que o RCD é mais esférico do que a escória de aciaria, o que pode ter colaborado para diminuir a resistência à deformação permanente justificando o resultado mais satisfatório para a mistura com escória de aciaria no ensaio de simulação. Além disso, os Vvs obtidos por Lopes et al. (2010) nas placas e nos CPs extraídos das placas mostram que a mistura I (100\% agregados naturais) apresentou maior Vv, seguida da mistura III (50\% escória de aciaria) e da mistura II (50\% RCD), o que obedeceu a ordem do ranking do ensaio de simulação e do PDI. As três misturas, que foram dosadas e compactadas no CGS, quando são levadas à mesa compactadora apresentam percentuais de Vv diferentes dos $4 \%$ obtidos com a compactação com 100 giros no CGS, ou seja, essa mudança no mecanismo de compactação gerou misturas com diferentes volumetrias e resistências à deformação permanente, no caso das misturas com resíduos. Acredita-se que, este fato influenciou na correlação entre TDI e ATR. Essa correlação apresentou $R^{2}=0,07$. 


\section{CONCLUSÕES}

Por meio da correlação com o ensaio uniaxial de carga repetida, concluiu-se que as variáveis CDI e TDI são parâmetros que podem ser utilizados para o estudo da resistência à deformação permanente em misturas com agregados naturais e com resíduos, sendo acessíveis de forma simples por meio do uso do CGS. A mistura contendo apenas agregados naturais (mistura I) mostrou-se com maior resistência à deformação permanente, apresentado menores valores de CDI, maiores valores de TDI e FN para amostras com 7\% de $\mathrm{Vv}$ em relação às misturas contendo $50 \%$ de escória de aciaria (mistura II) e 50\% de RCD (mistura III). A mistura com RCD apresentou, ainda, melhores valores de CDI, TDI e $\mathrm{FN}$ para amostras com $7 \%$ de $\mathrm{Vv}$ com relação à mistura com $50 \%$ de escória de aciaria, o que, nesse caso, poderia indicar que a utilização de RCD como agregado é mais favorável do que a utilização da escória de aciaria, no que diz respeito à deformação permanente. Os valores de FN para as amostras com 4\% de Vv apresentaram boas correlações com as variáveis TDI, porém a tendência da correlação apresentou-se diferente do esperado, o que indica que o ensaio de FN com essa porcentagem de $\mathrm{Vv}$ pode não ser representativo para a caracterização de misturas asfálticas com relação a deformação permanente.

Ao se levar as misturas compactadas no CGS para a mesa compactadora, a volumetria das mesmas e a resistência à deformação permanente mudaram consideravelmente, principalmente para as misturas com resíduos, não apresentando boas correlações com as variáveis de densificação. Isso foi concluído devido ao fato de que os resultados do PDI, do ensaio de simulação e as porcentagens de Vv das misturas compactadas na mesa compactadora apresentaram o mesmo ranking entre si, porém diferente daquele obtido com as variáveis de densificação e com os resultados dos ensaios de FN para amostras com 7\% de Vv. Esse novo ranking apresentou-se com a mistura I sendo melhor do que a mistura II, e a mistura II melhor do que a mistura III. Isso reforça, ainda, o fato de que é importante que o esqueleto pétreo da mistura seja bem estudado e considerado no nível de relevância da escolha da compactação da mistura.

\section{AGRADECIMENTOS}

Os autores agradecem ao Programa de Recursos Humanos da ANP para o Setor Petróleo e Gás (PRH-ANP/MCT) pelo apoio na forma bolsa de iniciação científica ao primeiro autor, e ao CNPq pelo apoio na forma de bolsa de iniciação científica ao segundo autor. Ao estudante de engenharia civil da UFC Lucas Feitosa Babadopulos pelo apoio no início da pesquisa. À equipe da Escola Politécnica da USP, sob a coordenação da Profa. Liedi Bernucci, pela concessão dos equipamentos utilizados para a confecção e ensaios das placas.

\section{REFERÊNCIAS BIBLIOGRÁFICAS}

ANP (2005) Resolução ANP $N^{o}$ 19, de 11.7.2005 DOU 12.7.2005. Regulamento Técnico $\mathrm{N}^{\circ} 3 / 2005$. Agência Nacional do Petróleo.

Antunes, F. F. L; V. T. F. Castelo Branco e J. B. Soares (2010) Avaliação dos impactos ambientais causados pela utilização em rejeitos ambientais em misturas asfálticas. $20^{\circ}$ Encontro de Asfalto - IBP, Rio de Janeiro, RJ.

Aragão, F. T. S.; Lutif, J.E.S.; Kim, Y.R.. Soares, J.B. (2007) Avaliação da zona de restrição como critério limitador em misturas asfálticas utilizadas em vias de baixo volume de tráfego. Anais da XXI ANPET, Rio de Janeiro, RJ.

Bahia, H. U. e A. Faheem (2007) Using the Superpave gyratory compactor to estimate rutting resistance of hot-mix asphalt. Transportation Research Board, n. E-C124 - Practical approaches to hot-mix asphalt design and production quality control testing.
Bahia, H. U.; P. P. Friemel e J. Russel (1998) Optimization of constructibility and resistance to traffic: a new design approach for HMA using the Superpave gyratory compactor. Journal of the Association of Asphalt Paving Technologists, v. 67, p. 189-232.

Bernucci, L. B.; L. M. Motta; J. A. P. Ceratti e J. B. Soares (2007) Pavimentação asfáltica: formação básica para engenheiros. Rio de Janeiro: PETROBRÁS: ABEDA.

Bessa, I. S.;V. T. F Castelo Branco e J. B. Soares (2009) Caracterização de agregados convencionais e alternativos utilizando técnicas de processamento digital de imagens. Anais da XXIII ANPET, Vitória, ES.

Dessouky, S.; E. Masad e F. Bayomy (2004) Prediction of hot mix asphalt stability using the Superpave gyratory compactor, Journal of $\mathrm{Ma}$ terials in Civil Engineering, v. 16, n. 6, p. 578-587.

DNER-ME 35 (1998) Agregados - determinação da abrasão "Los Angeles”. Método de Ensaio. Departamento Nacional de Estradas de Rodagem, Rio de Janeiro, RJ, Brasil.

DNER-ME 78 (1994) Agregado graúdo - adesividade ao ligante betuminoso. Método de Ensaio. Departamento Nacional de Estradas de Rodagem, Rio de Janeiro, RJ, Brasil.

DNER-ME 81 (1998) Agregados - determinação da absorção e da densidade de agregado graúdo. Método de Ensaio. Departamento Nacional de Estradas de Rodagem, Rio de Janeiro, RJ, Brasil.

DNER-ME 83 (1998) Agregados - análise granulométrica. Método de Ensaio. Departamento Nacional de Estradas de Rodagem, Rio de Janeiro, RJ, Brasil.

DNER-ME 84 (1995) Agregado miúdo - determinação da densidade real. Método de Ensaio. Departamento Nacional de Estradas de Rodagem, Rio de Janeiro, RJ, Brasil.

DNER-ME 86 (1994) Agregado - determinação do índice de forma. Método de Ensaio. Departamento Nacional de Estradas de Rodagem, Rio de Janeiro, RJ, Brasil.

Evangelista Jr., F.; L. T. Souza e J. B. Soares (2005) Processamento digital de imagens aplicado à caracterização de agregados quanto à forma. Anais da XIX ANPET, Recife, PE.

Fritzen, M.A. (2005) Avaliação de soluções de reforço de pavimentos asfálticos com simulador de tráfego na rodovia Rio Teresópolis. Dissertação (mestrado), COPPE/UFRJ, Rio de Janeiro, RJ.

Gonzalez, R. C. e R. E. Woods (1993) Digital image processing. AddisonWesley.

Lopes, M. M; I. S. Bessa; V. T. F. Castelo Branco e J. B. Soares (2010) Efeito do tipo de compactação nos parâmetros volumétricos e no comportamento mecânico de misturas asfálticas. Anais do $20^{\circ} \mathrm{En}$ contro de Asfalto, Rio de Janeiro.

Mahmoud, A. F. F. e H. Bahia (2004) Using the gyratory compactor to measure mechanical stability of asphalt mixtures. Wisconsin Highway Research Program, Project Number 0092-01-02.

Marques, G. L. O. (2004) Utilização do módulo de resiliência como critério de dosagem de mistura asfáltica; efeito da compactação por impacto e giratória. Dissertação (mestrado), COPPE/UFRJ, Rio de Janeiro, RJ.

Masad, E.; J. W. Button (2000) Unified imaging approach for measuring aggregate angularity and texture. Computer-Aided Civil and Infrastructure Engineering, p. 273-280.

Motta, L. M. G.; I. Tonial; L. M. Leite e R. S. Constantino (1996) Principios do projeto e análise Superpave de misturas asfálticas. Tradução Comentada, IBP.

Nascimento, L. A. H.; M. Chacur e L. F. M. Leite (2008) Uso do compactador giratório na previsão do desempenho de misturas asfálticas. Anais do $19^{\circ}$ Encontro de Asfalto IBP, Rio de Janeiro, RJ.

Nascimento, L. A. H. (2008) Nova abordagem da dosagem de misturas asfálticas densas com uso do compactador giratório e foco na deformação permanente. Dissertação (mestrado), COPPE/UFRJ, Rio de Janeiro, RJ.

NF P 98-253-1. (1991) Déformation permanente des melanges hydrocarbones. França.

NF P 98-250-2. (1991) Préparation des melangeshydrocarbones. França.

Shell (2003) The shell bitumen handbook ( $\left.5^{\mathrm{a}} \mathrm{ed}\right)$. London: Thomas Telford.

Silva, M. A. V. (2006) Comportamento de misturas asfálticas a quente utilizando agregado de argila calcinada. Dissertação (mestrado), IME, Rio de Janeiro, RJ.

Souza, L. T.; F. Evangelista Jr. e J. B. Soares (2006) Processamento digital de imagens aplicado a análise micromecânica de misturas asfálticas. Anais do $18^{\circ}$ Encontro de Asfalto IBP, Rio de Janeiro, RJ.

Souza, T. S. (2009) Investigation of aggregate angularity effects on asphalt concrete mixture performance using experimental and virtual asphalt samples. Dissertação (mestrado), University of Nebraska, Lincoln, NE. 
Tonial, I. e L. Leite (1995) Qualidade dos cimentos asfálticos brasileiros segundo as especificações SHRP. Anais do $12^{\circ}$ Encontro de Asfalto IBP, p. 94-119.

Viana, M. A.; M. A. Silveira; J. A. G. Vasconcelos; F. J. Chaves; J. Valdonel; J. F. P. Lima; J. A. A. Paiva; G. F. Rodrigues; L. M. Leite; I. Tonial e L. M. G. Motta (1996) Trecho experimental/CE: monitoramento do pavimento que testa a aplicação da especificação superpave na região nordeste. Anais do $13^{\circ}$ Encontro de Asfalto IBP.

Witczak, M. W.; K. Kaloush e T. Pellinen (2002) Simple performance test for superpave mix design. National Cooperative Highway Research Program NCHRP-465, Washington, D.C., EUA. 